\title{
REFLEXIONES EN TORNO A LA LITERATURA INFANTIL Y JUVENIL EN TIEMPOS DE COVID-19 (O LA LIJ SALE AL RESCATE)
}

\author{
REFLECTIONS ON CHILDREN'S LITERATURE IN TIMES OF COVID-19 (OR THE \\ CHILDREN'S BOOKS COMES TO THE RESCUE)
}

\section{Laura Codaro \\ Universidad Nacional de La Plata, Argentina lauritacodaro@hotmail.com}

Recibido: 19 de julio de 2021 Aprobado: 11 de septiembre de 2021 Publicado: 31 de diciembre de 2021

Cita sugerida: Cordero, L. (2022). Reflexiones en torno a la literatura infantil y juvenil en tiempos de COVID-19 (o la LIJ sale al rescate). Revista de la Escuela de Ciencias de la Educación, 1(17), 32-47.

\section{RESUMEN}

Este trabajo busca reflexionar sobre el papel de la literatura infantil y juvenil (LIJ) en tiempos de COVID-19. Para ello, se retoman algunas definiciones del género en cuestión y luego se exponen las características, los usos y las funcionalidades de la LIJ durante el primer año de esta pandemia, centrando la atención en lo que sucede en Argentina. A través de la revisión de distintos materiales producidos y divulgados en diferentes países de Latinoamérica y el análisis de un conjunto de materiales producidos por la Secretaría Nacional de Niñez, Adolescencia y Familia (SENAF) del Ministerio de Desarrollo Social de la República Argentina, con el apoyo del Fondo de las Naciones Unidas para la Infancia (UNICEF), se pretende mostrar cómo la LIJ cobra un rol preponderante ante este fenómeno extraordinario y sus consecuencias.

Palabras clave: LIJ - COVID-19 - Infancia - Latinoamérica - Argentina.

\section{ABSTRACT}

This paper wants to reflect on the role of children's literature in times of COVID19. For this, some definitions of this genre are retaken and then the characteristics, uses and functionalities of the juvenile literature in the first year of this pandemic are exposed, the most important for this article is what is happening in Argentina. Through the review of different materials produced and 
Revista de la Escuela de Ciencias de la Educación. 2022, Año 18 1(17) 32-47. Enero a junio. Cordero, $L$. Reflexiones en torno a la literatura infantil y juvenil en tiempos de COVID-19 (o la LIJ sale al rescate).

disseminated in different Latin American countries and the analysis of a set of materials produced by the National Secretariat for Children, Adolescents and the Family (SENAF) of the Ministry of Social Development of the Argentine Republic, with the support from the United Nations Children's Fund (UNICEF), it wants to show how the children's literature takes an important place in this extraordinary phenomenon and its consequences.

Keywords: Children's literature - COVID-19 - Childhood - Latin America Argentine.

\section{INTRODUCCIÓN}

A lo largo de los años, desde su surgimiento hasta su momento de mayor apogeo, su crecimiento y el conocido "boom", distintos actores entre los que es posible destacar a los docentes, los investigadores y el mercado editorial han definido la literatura infantil y juvenil (LIJ) (también conocida como literatura para niños) de distintas maneras. No obstante, la pandemia provocada por la enfermedad causada por la COVID-19, que puso en jaque y resignificó múltiples prácticas educativas y culturales, mostró que la literatura infantil y juvenil adquirió diversos usos y funcionalidades respondiendo a este contexto tan inusual como excepcional para todos.

Este trabajo se propone analizar y reflexionar sobre el papel de la literatura infantil y juvenil (LIJ) en tiempos de COVID-19. Se pretende demostrar que la LIJ cobra un rol relevante ante las consecuencias de la emergencia sanitaria, que puede notarse en las prácticas educativas, en las propuestas de múltiples instituciones, en los materiales expuestos en las redes sociales, entre otros espacios y herramientas. Para ello, en un primer momento se recuperan las principales definiciones del género en cuestión, que permitan historizar y situar estos textos en el campo literario y así, mirar la producción contemporánea. En un segundo momento, se exponen las características, los usos y las funcionalidades de la LIJ durante los primeros tiempos de la pandemia causada por el nuevo virus, es decir, el año 2020, a modo ilustrativo se toman ejemplos de distintas partes de Latinoamérica. Por último, para atender a lo que se viene desarrollando en Argentina, se revisa un conjunto de materiales producidos por el gobierno nacional sobre la infancia y la juventud, publicado en mayo de 2020. De este modo, se busca arribar a conclusiones que permitan reflexionar sobre la LIJ en este nuevo escenario y que ayuden a repensar lo que sucede en torno a la literatura para chicos en el resto de América Latina y en otros países durante esta pandemia.

\section{DESARROLLO}

\section{Acerca de la literatura infantil y juvenil en tiempos de COVID-19}

Considero necesario revisar algunas de las definiciones en torno a la literatura infantil y juvenil que se encuentran en distintos trabajos relevantes sobre el tema, para determinar cuáles son las características y las particularidades del género. En primer lugar, en uno de los manuales más reconocidos sobre el tema, $L a$ 
Revista de la Escuela de Ciencias de la Educación. 2022, Año 18 1(17) 32-47. Enero a junio. Cordero, $L$. Reflexiones en torno a la literatura infantil y juvenil en tiempos de COVID-19 (o la LIJ sale al rescate).

literatura para niños y jóvenes de Marc Soriano (1995), que funciona como una guía muy completa para conocer diversas cuestiones ligadas a estos textos, se parte de la certeza de que la literatura infantil se remonta a los tiempos antiguos y a la tradición oral. Luego pasó a la escritura y adquirió fines pedagógicos, así, hacia fines de siglo XIX se habla de la Edad de oro de este tipo de literatura. EI siglo $\mathrm{XX}$, con las grandes guerras y las dictaduras en Latinoamérica, produjo diferentes cambios en la producción, publicación y difusión de estos libros. Hacia los años noventa, los países tienen su propio mercado definido en materia de literatura infantil y juvenil, hay distintos autores reconocidos en este campo específico, desde la Academia se desarrollan múltiples investigaciones y espacios de formación ligados a la LIJ, se consolida un vasto público apasionado por estos materiales, fin, en el nuevo milenio, nadie ignora la existencia de este género en constante crecimiento.

Del mismo modo que el campo literario de la LIJ crece constantemente, es posible notar un auge significativo de la crítica literaria consagrada a estos textos desde la que también se intenta definir y reflexionar en torno a estos materiales. En este sentido, es imperante mencionar los grandes aportes de María Adelia Díaz Rönner con su trabajo Cara y cruz de la literatura infantil, publicado por primera vez en 1988 y reeditado en 2001. Allí ella sostiene que la LIJ debe ser abordada como y desde la literatura, para observar sus elementos y analizar el proceso de escritura. Además, marca una serie de intrusiones en el tratamiento de la LIJ que tienen que ver con el tono moralizante, los fines pedagógicos y la esquematización evolutiva, es decir, explica que distintas disciplinas como la psicología, la didáctica y la ética generan perturbaciones al momento de abordar y analizar los textos para niños. Estos "intrusos" que provocan distracciones del objetivo y la especificidad de este tipo de literatura, desvirtúan la esencia misma de la LIJ. En consecuencia, ésta frecuentemente termina al servicio de las Ciencias Sociales y de las Ciencias de la Educación, que se acercan a la infancia y a los libros con fines utilitaristas. Su planteo tuvo tal incidencia que, en el año 2000, Díaz Rönner se incorpora a uno de los volúmenes de la Historia crítica de la Literatura argentina con un artículo donde menciona al adulto - y a su voz "mayor" - también como intrusos. En ese trabajo propone cierto juego de palabras y conceptos entre "menor" y "mayor", para señalar que hay cierta desvalorización de los textos para chicos. En resumen, sus tempranas lecturas y sus postulados generaron un gran impacto en el campo de estudio de la literatura para niños y aún hoy resultan significativos.

En segundo lugar, se encuentran artículos que estudian el fenómeno a nivel local, como el libro Literatura infantil argentina. Infancia, política y mercado en la constitución de un género masivo donde Marcela Arpes y Nora Ricaud (2008) hacen referencia a la literatura infantil argentina como un género de masas y entienden que estos textos son un recorte dentro de la literatura que están destinados específicamente a niños y niñas, es decir, hay un autor que piensa y se dirige a un público infantil, así, realiza un pacto de lectura apelando a diferentes estrategias. El libro hace un recorrido por la historia de la LIJ en Argentina y destaca distintos rasgos que tienen que ver con los temas abordados, los personajes, los paratextos, los géneros y otros tantos elementos. Asimismo, los propios autores de obras para chicos se ocupan de reflexionar sobre la LIJ, 
Revista de la Escuela de Ciencias de la Educación. 2022, Año 18 1(17) 32-47. Enero a junio. Cordero, $L$. Reflexiones en torno a la literatura infantil y juvenil en tiempos de COVID-19 (o la LIJ sale al rescate).

como Graciela Montes (2001), quien en El corral de la infancia habla del surgimiento de este tipo de literatura, de las decisiones del mercado y del mundo editorial y de los verdaderos protagonistas, receptores de estos textos: los niños. Hay otros materiales que reflexionan desde las prácticas de escritura, se trata de docentes e investigadores del área de la didáctica y la enseñanza de la lengua y la literatura que indagan la producción, el uso y la recepción de la LIJ y emprenden una puesta en valor de estos textos. Es posible recuperar algunas de las ideas de Maite Alvarado, por ejemplo, compiladas en Escritura e invención en la escuela (2013), un libro donde presenta a la literatura para chicos como "el patito feo de la literatura" y subraya que, a diferencia de la literatura latinoamericana o la literatura argentina, aquí el concepto no parte del origen.

Por último, cabe nombrar a los distintos docentes que desde la Academia y por fuera de ella, en los últimos años se han interesado apasionadamente por estos temas en particular, han organizado jornadas, capacitaciones, cursos y diversos eventos que contribuyeron indudablemente a que la literatura para niños y niñas ocupe un lugar privilegiado en muchos programas escolares, en bibliotecas y librerías. Tal es el caso de Mila Cañón (2019), quien tiene un interesante recorrido ya que sus primeras inquietudes surgen de su formación inicial como maestra de grado, experiencia que la lleva a formular iniciales preguntas en torno a la constitución de este campo literario, el canon, las selecciones y las prácticas de lectura de la literatura para chicos. Cañón (2019), siguiendo lo propuesto por Chambers, otorga importancia a la "conversación literaria" en la cual una comunidad de lectores realiza descubrimientos valiosos en torno a la lectura de textos literarios ya que constató la importancia de aspectos subjetivos en el proceso de escucha-interpretación grupal, co-autoral en los niños.

En esta instancia y luego de este somero recorrido vale la pena preguntarse cómo se puede definir aquí este gran conjunto de textos. Indudablemente, no resultan esenciales las denominaciones (hablar de literatura para niños y niñas, literatura para chicos y jóvenes o literatura infantil no cambiaría notablemente los corpus a los que hacen referencia), pero sí parece importante considerar que son obras literarias que si bien pueden haber sido escritas para un lector que es un niño, los adultos frecuentemente se vinculan con ellas de distintas maneras, como madres/padres y docentes mediadores en la lectura, como investigadores que las abordan como objeto de estudio, como lectores que las eligen por placer, etc. En consecuencia, es posible observar que no debería limitarse ni restringirse la inimaginable recepción de estos textos ni los actores que se vinculan cotidianamente con ellos. Puede pensarse que, en realidad, lo temático define y atraviesa el género, así, parecen fácilmente identificables los personajes, los mundos, los ambientes, las situaciones y los desenlaces de los cuentos para niños. No obstante, también estas características y estos elementos van mutando y se van reinventando, la LIJ rompe sus propios límites en busca de otros horizontes que hacen que se deban revisar antiguas historias, nuevos espacios de circulación, otros autores, etc.

Como aquí se propone revisar, la literatura para niños y varios aspectos que la envuelven se fueron resignificando durante esta pandemia en curso, provocada por el nuevo virus que causa la enfermedad del coronavirus. 
Revista de la Escuela de Ciencias de la Educación. 2022, Año 18 1(17) 32-47. Enero a junio. Cordero, $L$. Reflexiones en torno a la literatura infantil y juvenil en tiempos de COVID-19 (o la LIJ sale al rescate).

Indudablemente, la primera consecuencia evidente es la irrupción casi total de la virtualidad en la vida cotidiana que condujo a que los textos literarios lleguen fundamentalmente a través de las pantallas: computadoras, teléfonos celulares, tablets y televisores han sido los nuevos y habituales contenedores y transmisores de los relatos leídos, ilustrados o acompañados de materiales audiovisuales, de la transcripción del texto o de la fotografía del libro. Así, la literatura para niños llega en estos tiempos a los hogares por iniciativa de la escuela y de otras instituciones que brindan talleres y actividades de formación y esparcimiento y por propios intereses e inquietudes familiares. Ahora bien, podría afirmarse que la literatura infantil y juvenil cobra una relevancia mayor y ocupa un lugar privilegiado entre las propuestas escolares y familiares ya que se transforma en una de las principales herramientas para explicar a los niños este fenómeno sanitario y sus consecuencias, a la vez que sirve como estrategia para generar momentos de placer y entretenimiento en este escenario conflictivo y traumático. La LIJ, entonces, llega a los hogares para quedarse, se presenta casi como un comodín utilizado por niños, adolescentes y adultos en diversas situaciones cotidianas de esta nueva normalidad. No obstante, probablemente con el afán de explicar y hablar del nuevo fenómeno sanitario, también ingresan otros materiales diversos que son presentados como literatura y, además, aparecen distintas intrusiones en el abordaje de estas ficciones para niños. En esta instancia vale la pena mencionar algunos aspectos del tratamiento de la literatura infantil en estos tiempos. En primer lugar, las características de algunos textos que emergieron en este tiempo se ligan, en mayor o menor medida, a aquella literatura que perseguía fines pedagógicos, puesto que estos nuevos relatos buscan explicar qué es el virus, de qué trata esta enfermedad, cuáles son las consecuencias y cómo se debe actuar para evitar el contagio y la propagación.

En otros términos, se forjan cuentos y materiales pedagógicos presentados como literatura, que podrían pensarse como estrategia para que los chicos puedan entender el fenómeno sanitario. Es posible encontrar decenas de relatos de distintos autores de todo el mundo (algunos son escritores reconocidos, otros son docentes de diversas instituciones u otros profesionales como psicólogos, puede haber equipos enteros detrás de la producción) que circulan en la web, tal es el caso de El escudo protector contra el rey virus de Guadalupe del Canto, Rosa contra el virus del Colegio Oficial de la Psicología de Madrid, Misión: quedarse en casa de Dalmus, Alicia y el coronavirus de Salvador Macip y Emilio Urberuaga, Coronavirus no es un príncipe (ni una princesa) de María Coco Hernando y Sara Ramírez, entre otros. En estos cuentos suele haber un protagonista, que puede ser un niño o una niña que se enfrenta a una situación atípica y extraña como es la llegada de un virus y debe aprender a convivir con él o bien luchar e intentar combatirlo. En otros textos, el protagonista es el virus que aparece en forma de rey malvado, monstruo u otro personaje con malas intenciones, hay niños o familias enteras que son los encargados de combatirlo, a veces incluso los lectores deben llevar a cabo esta misión.

En segundo lugar, otros relatos parecen ser pensados para acompañar y contener a los niños, así, emerge más bien una intención terapéutica ante una posible situación traumática. En consecuencia, la LIJ se constituye como elemento para abordar delicada y atentamente un tema que puede acarrear 
Revista de la Escuela de Ciencias de la Educación. 2022, Año 18 1(17) 32-47. Enero a junio. Cordero, $L$. Reflexiones en torno a la literatura infantil y juvenil en tiempos de COVID-19 (o la LIJ sale al rescate).

problemas psicológicos, se toca el miedo, la angustia, el desgano, la decepción, el enojo, entre otras emociones y sentimientos. Un ejemplo claro de esto puede ser la propuesta de UNICEF Ecuador, que presenta algunas explicaciones sobre cómo abordar la cuestión y luego un corpus de cuentos que son adaptaciones de la serie Cuentos que traen calma, producida frente al terremoto ocurrido en abril de 2016 en Ecuador. Moni se queda en casa, El canto de la Luna y El Monito Feliz son algunos de los títulos de estas historias que hablan del miedo, de las nuevas situaciones que enfrentan los chicos, etc. Del mismo modo, Los días en que todo se detuvo de Jordi Iñesta trabaja el impacto y la adaptación ante la nueva cotidianidad producida por el confinamiento o cuarentena, también es un relato basado en otro texto titulado El día en que todo se movió, diseñado en 2019 para abordar el terremoto de 2017 en México.

En tercer lugar, cabe señalar la producción y sobre todo la difusión de textos literarios para chicos que buscan ser un insumo para entretener a los niños que deben quedarse en casa. Así, por un lado, surgen nuevos relatos sobre todo en formato digital -dado que las publicaciones impresas sufrieron algunas dificultades y demoras en muchos países-, son historias que no se vinculan particularmente con la pandemia, sino que abordan otros temas, pero llegan oportunamente en estos tiempos en los que la lectura de textos literarios se hace más presente en los hogares. Se trata de materiales producidos por escritores reconocidos, pero también por autores amateurs, personas que se están iniciando en la escritura, otros profesionales (psicólogos, psicopedagogos, docentes, etc.) que incursionan en la ficción, padres y abuelos que narran, hay un conjunto heterogéneo de materiales que van apareciendo con más frecuencia. Por otro lado, se observa una mayor difusión y divulgación de textos ya editados, ya conocidos, que representa una invitación especial a acercarse a la literatura infantil, a la lectura de ciertos cuentos. Para ilustrar esto podrían mencionarse distintos ejemplos, uno harto interesante es la colección de UNICEF Argentina de noviembre de 2019 llamada Cuentos que cuidan, que contiene relatos de escritores e ilustradores de reconocida trayectoria: Silvia Schujer, Pablo Bernasconi, Graciela Repún y Paula Bombara. Si bien se trata de una propuesta lanzada antes del arribo del virus a Argentina, que aborda el derecho a la educación, la inclusión, la equidad, la salud y la protección a través de historias pensadas para la primera infancia, cobra una gran relevancia y cuenta con una amplísima difusión en 2020 para fomentar el diálogo familiar sobre estos temas y así concientizar a los chicos y sobre todo a los adultos sobre los derechos del niño. Esta decisión puede justificarse, en parte, por las diversas situaciones que atraviesan los niños en sus hogares que se ven potenciadas por el confinamiento, como los conflictos familiares y el abuso infantil, puesto que ciertamente son materiales que entretienen y divierten, pero sobre todo que educan y apelan a la toma de conciencia. Estas ficciones y otras obras de estos autores son representativas del campo literario para niños en Argentina, son los textos que muchos docentes, padres, chicos y adolescentes eligen para acercarse a la literatura.

Un cuarto aspecto a destacar tiene que ver con la difusión de estos relatos, materiales y propuestas por las redes sociales y por los numerosos canales virtuales que se usan cada vez más en estos tiempos. Si bien la circulación de la 
Revista de la Escuela de Ciencias de la Educación. 2022, Año 18 1(17) 32-47. Enero a junio. Cordero, $L$. Reflexiones en torno a la literatura infantil y juvenil en tiempos de COVID-19 (o la LIJ sale al rescate).

literatura y de los textos para niños en particular no es un fenómeno novedoso, las restricciones impuestas en distintos países llevaron a que las redes sociales y los portales digitales contengan más obras literarias. En lo que concierne a la LIJ, es posible notar que en estos espacios no sólo hay más relatos completos o fragmentados, sino que otras formas cobran mayor popularidad: los textos leídos en formato de audio, las producciones audiovisuales que buscan darle imágenes a alguna historia, los videos donde alguien (generalmente un adulto) lee un libro y va mostrándolo, etc. Esto acercó la literatura infantil a un gran número de lectores, entró a los hogares no sólo a través de las propuestas docentes sino de los padres e incluso de los propios niños y adolescentes, todos ellos usuarios de las nuevas tecnologías y de las redes sociales específicamente.

Para seguir revisando el papel de la LIJ en estos tiempos pandémicos y tomar un ejemplo concreto de este fenómeno en Argentina, en esta instancia se propone analizar cómo se presenta la literatura para chicos en un conjunto de materiales producidos por la Secretaría Nacional de Niñez, Adolescencia y Familia (SENAF) del Ministerio de Desarrollo Social de la República Argentina, con el apoyo del Fondo de las Naciones Unidas para la Infancia (UNICEF). Se trata de unas guías publicadas en mayo de 2020 en la página oficial del gobierno, bajo el título Guías de recomendaciones: actividades, recursos y cuidados para niñas, niños y adolescentes. Como allí se explica, los hipervínculos que conectan generalmente con archivos en pdf, pueden dividirse en dos grandes partes según su contenido: en primer lugar, las guías que presentan recomendaciones y propuestas para niños y adolescentes, divididas en tres partes atendiendo a los distintos momentos del desarrollo (Jugar en casa. Guía de recomendaciones, juegos y actividades para la primera infancia 1 y Jugar en casa. Guía de recomendaciones, juegos y actividades para la primera infancia 2 se ocupan de la primera infancia (hasta 4 años); Crear, aprender y divertirse en casa. Guía de recomendaciones y actividades para chicas y chicos atiende a niños de hasta 12 años; Entrá y divertite. Guía de recomendaciones y recursos para adolescentes está destinada a adolescentes); en segundo lugar, hay guías que contienen medidas de cuidado y prevención para chicos sin cuidados parentales y para aquellos que están en institutos penales juveniles. Para ver el uso que se hace de la literatura para chicos y chicas resulta adecuado revisar los documentos del primer grupo, todos ellos poseen propuestas que buscan entretener y educar, pero sobre todo acompañar a los niños y sus familias en este tiempo tan particular. Por eso, poseen una introducción y un conjunto de explicaciones y sugerencias adecuadas al público al que se dirige cada una. En los cuatro casos se presentan un conjunto variado de materiales que dialogan, en algún punto, con las propuestas curriculares: canciones, textos literarios, juegos, recetas de cocina, películas y otros documentos audiovisuales, entre otros. Para comenzar, la primera guía destinada a la primera infancia, Jugar en casa 1, presenta inicialmente cinco canciones de diferentes cantautores reconocidos, acompañadas por un video, y luego dos cuentos: Misión: quedarse en casa de Dalmus y Miedo de Graciela Cabal. El primer texto fue diseñado especialmente para trabajar en torno al coronavirus, la página sugiere visitar la página web donde se encuentra el relato en distintos idiomas: se trata de una producción mayoritariamente en blanco y negro que explica cómo actúa el virus y luego invita 
Revista de la Escuela de Ciencias de la Educación. 2022, Año 18 1(17) 32-47. Enero a junio. Cordero, $L$. Reflexiones en torno a la literatura infantil y juvenil en tiempos de COVID-19 (o la LIJ sale al rescate).

al lector a completar unas actividades, la última concluye cuando haya pasado el confinamiento. Ciertamente es un texto pensado para niños en el que el planeta toma la primera persona del singular y le habla a un "tú", que es un niño que representa a todos los niños del mundo, pero puede afirmarse que también involucra a los adultos, ya que es una propuesta para que alguien presente al niño, de hecho, al final se dirige directamente a los "papás, mamás y tutores". El segundo texto, en cambio, es un relato de una escritora argentina publicado en 1997 que propone pensar el tema de los miedos, ya no centrándose en una enfermedad. La obra presenta una estructura bastante tradicional: se inicia con "había una vez" y presenta a "un chico" que le tiene miedo a diferentes cosas y situaciones, hacia el final logra resolverse el problema dado que no tiene más miedo, "tiene perro", como se lee. La propuesta es verlo y escucharlo a través de un video del canal Pakapaka. Ahora bien, como se atendió en la descripción expuesta líneas atrás, aquí aparecen dos cuentos infantiles distintos por varios aspectos (el contexto de producción, el diseño, la trama, las ilustraciones, etc.) pero que son utilizados para abordar el tema de la COVID-19 y sus consecuencias con los niños pequeños. En consecuencia, emerge nuevamente el tratamiento utilitarista de la LIJ, que sirve para explicar y educar. Después de estos dos cuentos, se invita a visitar el canal infantil donde hay otros elementos útiles y se sugiere ver puntualmente dos series de videos: Cuentos de había una vez y Música para imaginar. A continuación, hay cinco juegos desarrollados para poner en práctica dentro del hogar y finalmente algunas recomendaciones a modo de cierre. Por su parte, la segunda guía ya más extensa, se inaugura con tres recetas de cocina, continúa con siete propuestas lúdicas diversas y luego llegan las canciones y los cuentos. Esta vez hay cuatro recursos literarios diferentes, aunque ninguno de ellos es producido específicamente para tratar la pandemia sino que, en su conjunto, parecen querer ofrecer un abanico de obras literarias que contenga cierta pluralidad de relatos: Minianimalitos cuenta historias de animales y hay también cuentos clásicos; Te quiero (casi siempre) de Anna Llenas es leído por Elena Santa Cruz, una docente que trabaja también en una hospital; Abel regala soles de Istvansch invita a dibujar en casa; El fruto azu/presenta una leyenda tehuelche. Es importante destacar que en todos los casos son los materiales audiovisuales los que presentan las obras literarias. Como puede observarse, aquí la LIJ ya no busca explicar el coronavirus sino reflexionar y fomentar la imaginación (como en las propuestas dos y tres) y fundamentalmente empezar a brindar conocimientos ligados al campo literario (el autor, los cuentos tradicionales y las leyendas son probablemente los conceptos más resonantes).

A continuación, hay cuatro canciones y luego indicaciones para higienizar y cuidar los juguetes.

Por su parte, la tercera guía titulada Crear, aprender y divertirse en casa. Guía de recomendaciones y actividades para chicas y chicos se abre con algunas explicaciones sobre el coronavirus. Entre los recursos utilizados para esta tarea se encuentran dos videos de Pakapaka (De Zamba y Niña), una canción y el texto ya mencionado El escudo protector contra el coronavirus de Guadalupe del Canto.

Luego hay nueve apartados que incluyen el canto, los juegos, las recetas de cocina y otras propuestas que buscan fomentar la creatividad. Es importante señalar que la literatura para niños ocupa el primer lugar, aunque aquí se hace 
Revista de la Escuela de Ciencias de la Educación. 2022, Año 18 1(17) 32-47. Enero a junio. Cordero, $L$. Reflexiones en torno a la literatura infantil y juvenil en tiempos de COVID-19 (o la LIJ sale al rescate).

una presentación que se acerca más a una especie de programa de obras literarias sugeridas que se encuentran en la web, que a una propuesta o guía de lectura. En efecto, hay dos páginas de Internet que funcionan como repositorios recomendados, el Plan Nacional de Lectura y la Biblioteca Nacional del Maestro, y de allí se compendian colecciones y obras de autores reconocidos, como Gustavo Roldán, Elsa Bornemann y Adela Basch. No obstante, éste no parece ser el principal criterio de selección dado que, en realidad, la lista recorre distintos géneros y subgéneros literarios, comienza por la poesía, continúa por las historietas, sigue con algunos cuentos y se detiene también en los mitos y relatos tradicionales. Al mismo tiempo, se pondera cierta clasificación de los materiales según la edad, para orientar a los adultos que deban invitar a la lectura o la escucha de estas historias. Finalmente, aparece algo sumamente interesante que responde al motor de esta guía: se presentan ideas para que los chicos inventen historias, no son consignas, sino que se espera que la persona adulta las adapte y las formule. En consecuencia, aquí la literatura para niños emerge como la primera herramienta para crear (un relato), aprender (los géneros y subgéneros literarios) y divertirse a través de textos ficcionales reconocidos y consagrados.

Por último, cabe aclarar que toda la guía se presenta como un conjunto de recursos que sirven de orientación para los adultos y no como actividades ya diseñadas para ser llevadas a cabo por los chicos.

La cuarta guía titulada Entrá y divertite. Guía de recomendaciones y recursos para adolescentes ya está destinada directamente a los verdaderos lectores del documento que son los adolescentes, es decir, no supone mediaciones. Desde el título y a lo largo de todo el archivo se construye una segunda persona del singular al que se le proponen lecturas, actividades, sitios de internet y otros elementos, usando un tono familiar y cercano, amigable y a veces coloquial. Asimismo, se acentúa el formato de la guía anterior, por lo cual, no hay consignas totalmente cerradas sino sugerencias y recursos disponibles para ser consultados y revisados. En este caso en particular, hay dos apartados dedicados a la literatura, el tercero y el cuarto, denominados Inspiraciones para leer y escribir y Hacer historietas y mandar mensajes respectivamente. Puede pensarse que también hay un corpus variado de textos: cuentos, novelas, revistas, reseñas, historietas y cómics, diarios o narraciones del "yo" aparecen mencionados en esta guía. En la tercera sección aparecen autores clásicos, infaltables en el canon literario escolar de las materias del área de cualquier diseño curricular para la escuela secundaria en Argentina, como Julio Cortázar, George Orwell, Oliverio Girondo y Elsa Bornemann. En cambio, la cuarta sección invita a conocer qué son las historietas y los cómics y a diseñar uno. Quizás el rasgo más distintivo de esta guía, que caracteriza la parte de literatura, pero recorre el resto de los apartados, es el uso de la tecnología, no por los hipervínculos que conducen a otros materiales y el uso de videos, como en las guías anteriores, sino que aquí la propuesta plantea el acercamiento a otras propuestas que ligan estrechamente la literatura a las nuevas tecnologías. Esto puede representar un abordaje novedoso, aunque, en realidad, se adapta a las dinámicas e intereses de muchos adolescentes. De este modo, al hablar de los "Booktubers Argentines" y presentar tres "rincones poéticos" para leer, escuchar y crear, "Susurro y Altavoz", "Girondo dice" y "Primal", se intenta cautivar a un 
Revista de la Escuela de Ciencias de la Educación. 2022, Año 18 1(17) 32-47. Enero a junio. Cordero, $L$. Reflexiones en torno a la literatura infantil y juvenil en tiempos de COVID-19 (o la LIJ sale al rescate).

lector joven que, sin dudas, tiene múltiples inquietudes, pero seguramente esté muy familiarizado con las nuevas tecnologías. No obstante, más allá de la originalidad de esta propuesta, es necesario señalar que hay escasos títulos y autores de la literatura para niños y niñas (probablemente Mil grullas de Elsa Bornemann sea el único), tampoco se encuentran textos contemporáneos, por el contrario, en su mayoría se trata de obras tradicionales del canon literario escolar.

Por último, la guía continúa con propuestas de música, películas y otros materiales que, de igual manera, parecen dialogar con las propuestas curriculares.

Ahora bien, tratando de analizar en conjunto estas guías realizadas tempranamente por la Secretaría Nacional de Niñez, Adolescencia y Familia (SENAF) del Ministerio de Desarrollo Social de la República Argentina, puede afirmarse que la literatura ocupa un lugar privilegiado al momento de pensar materiales para entretener y educar a los chicos. Más aún, la mayoría de los títulos y autores escogidos pertenecen a la LIJ. De este modo, el lector, que será el adulto mediador en las tres primeras guías y el adolescente en el último caso, se encuentra rápida y fácilmente con un abordaje interesante y novedoso de obras literarias conocidas, que se entrecruzan con otros lenguajes artísticos, otros recursos y herramientas digitales. En efecto, la literatura se configura como un elemento imprescindible para hablar de la pandemia con los niños, pero también para entretenerse y divertirse durante el confinamiento, a la vez que no deja de enmarcarse en propuestas que buscan abordar conceptos y conocimientos del campo literario. En este sentido, cabe señalar la vinculación entre la LIJ y los diseños curriculares, que son los documentos oficiales confeccionados por el gobierno para que los docentes y los equipos de gestión trabajen en las diferentes asignaturas de la escuela. Si bien esto se observa pronunciadamente en la última guía donde los autores y las obras literarias coinciden con los expuestos en el canon literario escolar, también puede notarse que la mayoría de los temas, las actividades, los abordajes y las lecturas de todos los documentos parecen estar bajo la sombra de conocidas prácticas escolares. Así, se trabaja en torno a los cuentos tradicionales, las leyendas, las historietas más populares, se escuchan relatos leídos por docentes o se invita a cambiar el desenlace de una historia.

Indudablemente, el hecho de presentar propuestas similares a las que los chicos suelen desarrollar en la escuela facilita la tarea de los adultos que funcionan como mediadores (generalmente las madres o los padres), y sitúa a los alumnos en situaciones en algún punto familiares para ellos. Estos pueden ser, entonces, aspectos que beneficien la recepción de los materiales en los hogares.

Otro punto de las guías para señalar es que, en su conjunto, muestran cierta continuidad y progresión no sólo en los temas abordados sino en el desarrollo de las propuestas: mientras que, en las primeras, la LIJ parece ser el vehículo para explicar la pandemia, esto poco a poco va cambiando y se transforma en un recurso para entretener y enseñar. En los más pequeños, los adultos serán quienes lean y presenten los materiales, pero luego se intenta generar cierta autonomía, en primer lugar, en los padres o mediadores que pueden adaptar, elegir o formular las actividades y en segundo lugar, en los chicos y adolescentes que ya emprenden solos las lecturas. 
Revista de la Escuela de Ciencias de la Educación. 2022, Año 18 1(17) 32-47. Enero a junio. Cordero, $L$. Reflexiones en torno a la literatura infantil y juvenil en tiempos de COVID-19 (o la LIJ sale al rescate).

Luego de describir cómo se configura la literatura para niños y adolescentes durante la pandemia en curso, se retoman las definiciones expuestas inicialmente para ver las posibles continuidades y rupturas que se conciben, cómo puede situarse el uso de la LIJ en este contexto de emergencia. Por un lado, cabe destacar que, en este caso y de distintas maneras, la pandemia aparta la idea de la LIJ como un género "menor", como exponía Díaz Ronner, puesto que la gran mayoría de las propuestas de los distintos gobiernos, de los organismos reconocidos e incluso de otras instituciones menores escogen los textos literarios para hablarles a los niños del coronavirus y para desarrollar diversas actividades. Aparecen algunas cuestiones que marcaba la autora, por un lado, la desvalorización o cierta tergiversación de la LIJ que conduce a presentar algunos materiales como literatura, cuando en realidad se acercan más a la herramienta pedagógica. No obstante, más allá de las posibles tensiones entre lo que se considera (o no) literatura, habría un claro uso con fines pedagógicos, Misión: quedarse en casa de Dalmus y El escudo protector contra el rey virus de Guadalupe del Canto son los cuentos escogidos por las guías analizadas, pero hay otros textos literarios utilizados por otras instituciones. De este modo, aparecen estas intrusiones de la Psicología y la Pedagogía que producen un efecto nocivo en este campo de estudio. En la misma línea, se encuentra la esquematización evolutiva, este fenómeno es bien claro en las guías donde se dividen las obras literarias según la edad. Esto se acentúa más aún en los textos literarios infantiles sobre la pandemia, que suelen reservarse para hablar del coronavirus con los más pequeños, mientras que los adolescentes reciben explicaciones a través de textos expositivos: ¿acaso la lectura de esas obras literarias es exclusiva de la primera infancia?, ¿ipor qué no pueden invertirse 0 combinarse los materiales? Por otro lado, volviendo a los planteos de Arpes y Ricaud, también a los de Montes, ya mencionados, emergen las representaciones de la LIJ como un género de masas y las demandas editoriales. Como puede observarse, iniciada la pandemia se produjo un amplio abanico de materiales culturales, artísticos y educativos, más puntualmente, aparecieron relatos sobre el virus, algunos completamente nuevos y otros frutos de adaptaciones (como los casos nombrados de Ecuador y México), que lograron publicarse generalmente de forma digital o simplemente empezaron a circular en los portales y las redes. Asimismo, se difundieron otros títulos y otros autores, algunos fueron utilizados en esta ocasión para repensar las consecuencias del virus (Miedo de Graciela Cabal puede ser un buen ejemplo) pero otros buscaban entretener o enseñar. Así, la LIJ respondió a una necesidad sanitaria pero también escolar, editorial, social, familiar, salió al rescate de los niños y por qué no de los adultos.

Tomando esta última idea, vale la pena repensar en la conocida definición de literatura para chicos, que supone un destinario que es un niño. Si bien la pandemia y el confinamiento no dejaron de lado esta idea, es posible notar que muchos de los relatos y los materiales forjados para explicar el coronavirus están dirigidos a la familia en su conjunto, esperan uno o varios adultos mediadores que no sólo acompañen o emprendan la lectura del texto sino asistan con las actividades que se proponen hacia el final, amplíen con otras explicaciones, contengan y estimulen el trabajo con esos materiales. Por ello, de alguna manera 
Revista de la Escuela de Ciencias de la Educación. 2022, Año 18 1(17) 32-47. Enero a junio. Cordero, $L$. Reflexiones en torno a la literatura infantil y juvenil en tiempos de COVID-19 (o la LIJ sale al rescate).

podría pensarse que estas herramientas suponen la "intrusión" del adulto. Tal es el caso de El escudo protector contra el Rey Virus de Guadalupe del Canto, que contiene Recomendaciones para mamás, una lista de sugerencias encabezadas por un párrafo donde se especifica con claridad que el cuento fue desarrollado para ayudar a las mamás a conversar sobre el tema con los niños, o bien de Misión: quedarse en casa de Dalmus, dado que al final les habla a "Papás, mamás y tutores". En otros casos, se trata de textos infantiles presentados por algún organismo como UNICEF, donde hay una propuesta extraliteraria para trabajar en torno al virus y se brinda un conjunto de materiales, herramientas y explicaciones para los padres por fuera de la historia pero que, de algún modo, enmarcan o contextualizan la lectura. De esta manera, puede afirmarse que el adulto también es el destinatario de estos relatos, no sólo por ser el mediador, sino que, en este caso, con las recomendaciones, sugerencias y explicaciones, los autores y las instituciones se dirigen directa o indirectamente a los padres.

Asimismo, aparece la imagen del adulto lector que se acerca a la literatura infantil y aprende, comprende y por qué no, disfruta de ella, la LIJ que derriba fronteras y entra en los hogares, interpelando y generando placer en toda la familia.

Por otro lado (pero siguiendo con la recepción de los textos), es necesario destacar que la LIJ supo adaptarse asombrosamente al escenario virtual que presentó el confinamiento y a los intereses y las circunstancias de sus principales destinatarios: niños, niñas y adolescentes que forman parte de una generación nacida a la luz de las nuevas tecnologías y que, producto del COVID-19, tuvieron que quedarse en sus casas y utilizar aún más los dispositivos tecnológicos para comunicarse con otros, para aprender, para entretenerse, etc. Si bien este fenómeno LIJ 2.0 (Literatura y Lectura Infantil y Juvenil en la web social) no es nuevo, como analizan José Rovira-Collado y Mirena D. Ivanova (2019), múltiples actores e instituciones apelaron a él en todo el mundo durante los años 2020 y 2021 y potenciaron su producción, su uso y su divulgación. Para ilustrar esto, pueden mencionarse la mayoría de los relatos aquí expuestos, que surgieron en formato digital o se adaptaron a las pantallas: hay archivos fácilmente descargables que permiten la lectura desde cualquier dispositivo; otros están listos para ser impresos y poder ser completados o coloreados; algunos tienen un video o un archivo sonoro que contiene la lectura en voz alta. Del mismo modo, las guías estudiadas proponen materiales que están completamente atravesados por la web, como se observa, por ejemplo, en Entrá y divertite. Guía de recomendaciones y recursos para adolescentes, donde se habla de los Booktubers y se exhiben páginas interactivas para jugar con las palabras. Indudablemente, esta doble mirada puesta en las situaciones provocadas por la emergencia sanitaria y en los destinatarios de los textos implicó notables desafíos en los autores, los docentes, las instituciones, etc.

El último punto que aquí se destaca tiene que ver con los lazos que unen a estas propuestas al canon literario escolar. Como se ha comentado, desde la Academia diferentes investigadores han estudiado la formación y las características del corpus de textos literarios y no literarios que circulan en las aulas. En líneas generales, puede afirmarse que, si bien hay autores de literatura para niños, también hay obras clásicas, escritores célebres de la literatura 
Revista de la Escuela de Ciencias de la Educación. 2022, Año 18 1(17) 32-47. Enero a junio. Cordero, $L$. Reflexiones en torno a la literatura infantil y juvenil en tiempos de COVID-19 (o la LIJ sale al rescate).

nacional, relatos de la tradición oral, un conjunto heterogéneo de títulos. Lo interesante es que tanto estos rasgos del canon literario escolar como los saberes que atraviesan el currículum pensado para abordar la literatura, parecen dialogar estrechamente con los planteos que surgen para trabajar con los niños en los hogares en tiempos de COVID-19. Las guías producidas y divulgadas desde UNICEF Argentina pueden servir para ver este fenómeno a nivel local. En efecto, pueden enumerarse aspectos que aparecen en los diseños curriculares de la provincia de Buenos Aires, desde el nivel inicial hasta la escuela secundaria: la escucha y la lectura de textos literarios diversos; el reconocimiento de los distintos géneros; el acercamiento a la tradición oral (mitos y leyendas); el abordaje de historietas; el trabajo en torno a propuestas de comprensión de texto, análisis crítico y producción individual y colectiva; los autores reconocidos de LIJ en Argentina como Elsa Bornemann, Gustavo Roldán y Adela Basch, que también forman parte de la lista sugerida por el Diseño Curricular para el Educación Primaria; los escritores del canon literario escolar que presentan los Diseños Curriculares para la Educación Secundaria en el área de Literatura, como Julio Cortázar, Oliverio Girondo y George Orwell. Por ello, puede afirmarse que las guías y los materiales confeccionados conservan fines educativos específicos que se enmarcan en las propuestas oficiales del Ministerio de Educación, aunque no estén pensadas para ser trabajadas como contenidos curriculares en sí mismos. En cuanto a la literatura para chicos y adolescentes, ésta se entrecruza con otras obras y otras herramientas, lo cual da a entender que no debe ser abordada separadamente del resto de los títulos, sino que tiene que someterse a un análisis literario y crítico, como aquellos relatos escritos para adultos.

Asimismo, a diferencia de lo que sucede con los diseños curriculares, que hacen referencia a la literatura en términos muy generales y las sugerencias de títulos y autores aparecen al final, aquí los textos literarios para niños ocupan el lugar central y a partir de ellos se piensan otras cuestiones.

\section{CONCLUSIÓN}

A lo largo de este trabajo se intentó demostrar cómo, durante esta pandemia en curso, la literatura para niños y adolescentes derribó, una vez más y de distintas maneras, las fronteras del género y las definiciones que desde distintos espacios se le han atribuido. Ante una situación de emergencia sanitaria se han producido, publicado y puesto en circulación distintos textos y materiales que mostraron las múltiples características que la LIJ puede tener: relatos que vuelven al tono didáctico-moralizante, cuentos usados con fines más bien terapéuticos, aplicaciones o herramientas tecnológicas que hablan de la LIJ 2.0, historias que llegan en audio o en video. Estos son algunos de los usos que caracterizan a los textos para niños de estos tiempos. Aquí se sostiene que, en realidad, el arte y este tipo de literatura en particular, supieron adecuarse y reinventarse rápidamente para salir al rescate de un vasto número de niños, niñas y adolescentes de todo el mundo, que repentinamente debieron dejar sus hábitos para confinarse en sus casas y aprender a vivir de otras maneras. Si embargo, es necesario adoptar un punto de vista crítico con los materiales producidos y remarcar, por ejemplo, el efecto nocivo que produce sobre esta temática las 
Revista de la Escuela de Ciencias de la Educación. 2022, Año 18 1(17) 32-47. Enero a junio. Cordero, $L$. Reflexiones en torno a la literatura infantil y juvenil en tiempos de COVID-19 (o la LIJ sale al rescate).

intrusiones de distintas de disciplinas, el abordaje utilitarista de los relatos infantiles o la presentación de la LIJ como subsidiaria de las asignaturas del área de Lengua y Literatura. Sin dudas, estas cuestiones, que aún deterioran el campo de la literatura infantil, provienen de raíces históricas difíciles de desterrar, incorporadas en las matrices personales y socialmente difundidas y aceptadas.

Con respecto a los destinatarios, los niños no son los únicos lectores de las propuestas y los textos, sino que los adultos cobran un rol central como mediadores, pero también como lectores, dado que esta literatura que entretiene, enseña, explica y educa los invita a acercarse e incluye a toda la familia. En este sentido, puede pensar que la pandemia sí cuestiona de alguna manera la idea del niño como único y principal receptor de estos textos, que también son leídos y disfrutados por los adultos.

Finalmente, las circunstancias sanitarias van cambiando al igual que la situación de millones de familias, por ello, los rasgos y las funcionalidades de la literatura para chicos probablemente continúen transformándose, lo cual ameritará nuevos estudios y reflexiones sobre el tema, de hecho, aquí se presenta una aproximación a la producción de 2020 pero quedaría ver, por ejemplo, qué sucede en 2021. No obstante, ya no quedan dudas de que la LIJ no resiste el confinamiento, sino que, a través de las tramas y las historias, invita a salir y conocer otros mundos posibles.

\section{REFERENCIAS}

Alvarado, M. (2013). Escritura e invención en la escuela. Fondo de Cultura Económica.

Arpes, M. y Ricaud, N. (2008). Literatura infantil argentina. Infancia, política y mercado en la constitución de un género masivo. La Crujía.

Cañón, M. (2019). El campo de la literatura para niños y niñas. Miradas Críticas. Facultad de Humanidades UNMDP.

Chambers, A. (2007). Dime. Los niños, la lectura y la conversación. Fondo de Cultura Económica.

Codaro, L. (2020). La deconstrucción del canon literario escolar: estrategias y propuestas docentes hacia la subversión. Un viaje a través de las culturas letradas subversivas y de resistencia. Fondo Editorial CELEI, 63-78.

Díaz Rönner, M. A. (1988). Cara y cruz de la literatura infantil. Libros del Quirquincho.

Díaz Rönner, M. A (2000). Literatura Infantil: de menor a mayor en Historia crítica de la literatura argentina. Emecé.

Montes, G. (2001). El corral de la infancia. Fondo de Cultura Económica.

Rovira-Collado, J. e Ivanova, M. D. (2019). Educación literaria y lij 2.0 ante la internet de la imagen: bookstagramers, booktubers y otras redes de lectura. E-SEDLL (1), 99-118.

Soriano, M. (1995). La Literatura para niños y jóvenes. Guía de exploración de sus grandes temas. Colihue.

\section{Fuentes}


Revista de la Escuela de Ciencias de la Educación. 2022, Año 18 1(17) 32-47. Enero a junio. Cordero, L. Reflexiones en torno a la literatura infantil y juvenil en tiempos de COVID-19 (o la LIJ sale al rescate).

Bernasconi, P. "¿Qué vas a llevar?". Cuentos que cuidan, UNICEF Argentina. Disponible en: https://www.unicef.org/argentina/media/6741/file/\%C2\%BFQu\%C3\%A9 \%20vas\%20a\%20llevar?.pdf

Bombara, P. "El lunes conocí a Emi". Cuentos que cuidan, UNICEF Argentina. Disponible en: https://www.unicef.org/argentina/media/6731/file/El\%20lunes\%20conoc $\%$ C3\%AD\%20a\%20Emi.pdf

Cano, M. y otros. "El día en que todo se movió". Disponible en: https://1cae4daa431a99d58259-

9bdc952f8135a71056243221595a2db3.ssl.cf1.rackcdn.com/0E41FB6862F A4B7E9F6112FD59290E7F.pdf

Colegio Oficial de la Psicología de Madrid. "Rosa contra el virus." Disponible en: https://www.copmadrid.org/web/img_db/publicaciones/rosa-contra-elvirus-cuento-para-explicar-a-los-ninos-y-ninas-el-coronavirus-y-otrosposibles-virus-5e72423588003.pdf

Dalmus. "Misión: quedarse en casa". Disponible en: http://www.codajic.org/sites/www.codajic.org/files/Cuento\%20Mision\%2 Oquedarse\%20en\%20casa.pdf.pdf

del Canto, Guadalupe. "El escudo protector contra el rey virus". Disponible en: http://aapi.org.ar/wp-content/uploads/2020/03/El-escudo-protectorcontra-el-Rey-Virus.pdf

Dirección de Fortalecimiento y Formación en Primera Infancia. Subsecretaría de Primera Infancia. Secretaría Nacional de Niñez, Adolescencia y Familia. Jugar en casa. Guía de recomendaciones, juegos y actividades para la primera infancia 1.1 Disponible en: https://www.argentina.gob.ar/sites/default/files/guia_jugar_en_casa_pri mera_infancia_1.pdf

Dirección de Fortalecimiento y Formación en Primera Infancia. Subsecretaría de Primera Infancia. Secretaría Nacional de Niñez, Adolescencia y Familia. Jugar en casa. Guía de recomendaciones, juegos y actividades para la primera infancia 2. Disponible en: https://www.argentina.gob.ar/sites/default/files/guia_jugar_en_casa_pri mera_infancia_-_senaf_covid19.pdf

Dirección de Fortalecimiento y Formación en Primera Infancia. Subsecretaría de Primera Infancia. Secretaría Nacional de Niñez, Adolescencia y Familia. Crear, aprender y divertirse en casa. Guía de recomendaciones y actividades para chicas $y$ chicos. Disponible en: https://www.argentina.gob.ar/sites/default/files/guia_crear_aprender_y_ divertirnos-_senaf_covid19_0.pdf

Dirección de Fortalecimiento y Formación en Primera Infancia. Subsecretaría de Primera Infancia. Secretaría Nacional de Niñez, Adolescencia y Familia. Entrá y divertite. Guía de recomendaciones y recursos para adolescentes. Disponible

en: https://www.argentina.gob.ar/sites/default/files/guia_entra_y_divertite_fi nal_2.pdf 
Revista de la Escuela de Ciencias de la Educación. 2022, Año 18 1(17) 32-47. Enero a junio. Cordero, L. Reflexiones en torno a la literatura infantil y juvenil en tiempos de COVID-19 (o la LIJ sale al rescate).

Hernando, María Coco "Coronavirus no es un príncipe (ni una princesa)". Disponible en: https://www.yumpu.com/es/document/read/63156813/coronavirus-noes-un-principe-ni-una-princesa

Iñesta, J. Los días en que todo se detuvo. Disponible en: http://www.codajic.org/sites/www.codajic.org/files/Los\%20d\%C3\%ADas \%20en\%20que\%20todo\%20se\%20detuvo.pdf

Macip, S. y Urberuaga, E. "Alicia y el coronavirus". Disponible en: https://www.dropbox.com/s/c4ri5zdtek5g6w3/Ebook_Alicia_y_el_corona virus_ES.pdf?dl=0

Repún, G. "Los Guardasecretos". Cuentos que cuidan, UNICEF Argentina. Disponible en: https://www.unicef.org/argentina/media/6736/file/Los\%20guardasecreto s.pdf

Schujer, S. "Cuando se van al jardín". Cuentos que cuidan, UNICEF Argentina. Disponible en: https://www.unicef.org/argentina/media/6726/file/Cuando\%20se\%20va n\%20al\%20jard\%C3\%ADn.pdf

UNICEF Ecuador. "El monito Burbuja", Cuentos que traen calma. Disponible en: https://www.unicef.org/ecuador/informes/el-monito-burbuja-aprendecombatir-al-coronavirus

UNICEF Ecuador. "Moni se queda en casa", Cuentos que traen calma. Disponible en: https://www.unicef.org/ecuador/media/4626/file/Ecuador_moni_se_qued a_casa.pdf.pdf

UNICEF Ecuador. "Monita Pis Pis", Cuentos que traen calma. Disponible en: https://www.unicef.org/ecuador/media/4651/file/Ecuador_monita_pis_pi s.pdf.pdf

UNICEF Ecuador. "El canto de la Luna", Cuentos que traen calma. Disponible en: https://www.unicef.org/ecuador/informes/el-canto-de-la-luna

UNICEF Ecuador. "El Monito Parlanchín", Cuentos que traen calma. Disponible en: https://www.unicef.org/ecuador/informes/el-monitoparlanch\%C3\%ADn

UNICEF Ecuador. "El Monito Feliz", Cuentos que traen calma. Disponible en: https://www.unicef.org/ecuador/informes/el-monito-parlanch\%C3\%ADn 